\title{
Information Management
}

\section{Abstract}

After completing this learning unit, you will be able to:

- Identify the requirements for the use and organisation of information;

- Compare different types of citation;

- Analyse different ways of building the bibliography; and

- Identify different identification elements according to international publishing codes.

\section{Keywords}

Information management $\cdot$ Citation types $\cdot$ Publishing codes

\section{Summary}

Information management means using information obtained during a documentation process with the help of standards of ethical use of information and also computerised systems for preserving information regarding the sources used and for an automatic generating of references.

The third component of Information Literacy is information use and communication.

In information using and communication, several requirements should be fulfilled, as shown in detail in Fig. 8.1. 


\section{Information use}

- To find new ways in transmitting, presenting and using information

- To use the retrieved information

- To personalize the retrieved information

- To present the new informational product

\section{Communication and ethical use of information}

- To understand the ethical aspect in using information

- To respect legal provisions concerning the information use

- To respect intellectual property

- To use standards for references

Fig. 8.1 Information use

\subsection{Using Information in the Research Process}

\subsubsection{Role of Citation Process}

Citations and references are mandatory elements for any scientific paper. A citation represents the most effective way of establishing a relationship between current scientific ideas and the previous ones, by means of which the relevance of an author's work on a certain topic is appreciated and publicly recognised. By citation, the copyright requirements are observed, avoiding plagiarism, which is considered a violation of an author's professional ethics.

Any scientific paper involves citations based upon the scientific literature. Use of references in scientific papers is a part of academic code of behaviour.

References are bibliographic information about each quote or borrowed idea mentioned within the text of a paper, required to identify and retrieve the referenced work and check the accuracy of citation. A list of citations is usually found at the end of a scientific paper.

Using references is useful for fulfilling the following requirements:

Proof of adherence to academic writing standards;

Respecting the work of other researchers (avoiding plagiarism);

Offering proofs regarding consideration and analysis of relevant literature;

Validation and acknowledgment of sources used in the paper; and

Proofing the work's credibility. 
References are used in the following situations:

Another person is cited word by word using quotation marks (direct citation). It does not matter if it concerns a phrase, sentence or paragraph, the reference of the source must be given;

A citation is done by paraphrasing or summarising the ideas or data obtained from other sources;

Use of statistics obtained from other sources in the paper;

Use of tables, figures, diagrams or images created by someone else;

Use of controversial facts, opinions or data from other sources;

Information of general nature, and generally recognised facts should not be listed in the references (for example the years of the Second World War).

One needs to know the rules for creating a bibliographic description in the following situations:

Compiling a list of references on a requested topic;

Correct indication of the sources used in writing an essay, report, communication, undergraduate thesis, or year dissertation.

References became a very important tool in studying science itself and are used to investigate information flow. The number of citations is an indicator of a publication's quality and the scientific level of researchers work. An analysis of citations represents one of the scientometric/bibliometric research methods. The impact of a journal is measured by its number of citations in published articles. The higher the number of citations then the higher the number of persons using it as an information source and so its value for the topic.

\subsubsection{Principles of Describing Information Sources}

Before citing sources in a scientific paper, the researcher should know some descriptive principles related to citation: (Standardisation 1996)

- Bibliographic elements are extracted from the title page or the page equivalent to it (such as verso of title page, printing box, audio recording label);

- Bibliographic elements are recorded in the original language as they appear in the source;

- For non-Latin characters (Cyrillic, Arabic, Japanese or Chinese) transliteration is required according to international standards;

- Bibliographic elements are separated by a coherent punctuation system: period, comma, or colon;

- The author of a cited paper should be written in the following order: name, surname; 
- For two-three authors of a paper, their name should be separated by semicolon and space;

- For more than three authors, the abbreviation [et al.] is used after the first author;

- If the author of an information source is anonymous then the source title is the input element for the reference;

- The input element of a reference (author or information source title) should be distinctly marked in comparison to the other bibliographic elements (using bold characters, italics or underlined);

- The sub-title of an information source will be mentioned after the title using a colon and space;

- Additional information or spelling errors may be marked within square brackets after the changed bibliographic element;

- The transliterated form of an information source title can be used instead the original form or within parentheses after it;

- For unknown publishing dates there are standard expressions: [s.l.], for unknown publishing location, [s.n.], for unknown editor's name or [s.a.], for unknown publishing date;

- For information sources that are to be published, one may use the expression "publication in progress", while for the those not yet published, the expression "unpublished manuscript";

- For electronic information sources, whose bibliographic data is not complete, alternative information sources should be used; and

- The order of references may be alphabetical (for references), according to the input element or numerical (list of references), following the order of citations as referenced in the text.

\subsubsection{Citation Methods}

SR ISO 690:1996 standard indicates two citation methods of information sources: numerical citation method (or Vancouver style) and the method of citing the first element and the publication date (or Harvard style).

\subsubsection{Numerical Citation Method (Vancouver Style)}

This method refers to a counting system that uses numbers, inserted into the content of a scientific work, between parentheses or in exponent form.

When notation in parentheses is used, the numbers inside them will be associated to the information sources in the references list, numerically ordered. Endnotes are the implementation solution of this method.

When exponent notation is used (Fig. 3.2), the inserted numbers will indicate the cited information sources, placed in a footnote at the bottom of the page. Footnotes or chapter endnotes are the implementation solution for this method. 
In order to better understand the insertion of endnotes or footnotes, the researcher working on a scientific paper should be aware of some basic principles:

- If an information source is cited several times, a different number will be allocated to a note for each citation;

- A note can be used to cite either one information source or several information sources for the same referenced idea; (Ursachi and Scutelnicu 2011); and

- A note referring to a previous cited document should include either the entire citation or the number of the previous note followed by the page number (citation location).

In order to avoid repetition of some elements of bibliographic description, the following terms of Latin origin, standardised abbreviations, are used in citations:

- Apud(apud) = "quote after" Indicates a quote taken not from the original source but from another work citing it. The term "Apud" will be placed at the beginning of the quote, also indicating the loan source.

- Ibid. (Ibidem) = "In the same paper" or "Also there" In the immediate succession of citations, the text of the repeated quote is omitted, being replaced by the Latin term Ibidem, short form ibid. or even ib., written in italicised characters. This allows avoiding successive repetition of same citation.

In repeated quoting of another page of the same source, the page number is added to the word "Ibidem"; in a repeated citation in a volume, the volume number is added to the word "Ibidem".

- Id. (Idem) = "Same" (about the author). In the immediate succession of citations of different papers belonging to the same author, the term Idem or Id. will be used written in italics.

- When the same study of an author is cited several times in the paper, but not successively, the first citiation is made completely, then afterwards the Latin term opus citatum, is used, short form: op. cit., in italics, or underlined. In order to retrieve the reference of "op. cit.", the previous notes or the general section of references will be reviewed, looking for the first citation of the author.

For a repeated quote on another page, the page number will be added to "op. cit."; for the repeated citation in another volume (part, edition), the volume number is added to "op. cit.".

- contra = "contra". The reference is made to papers embracing opposing ideas or theses to the ones supported by the author in his paper. 


\subsubsection{Citation of the First Element and Publishing Date Method (Havard Style)}

If the author's name is mentioned in the text, then the date of publication will be inserted within parentheses. Otherwise, both bibliographic elements are written within parentheses.

The page number may also be added (from where the quote was taken) after the date of publication.

In the case of several documents with the same author and same publishing date, letters may be used additionally in order to distinguish between information sources.

\subsection{Citation Styles}

Citation of information sources in a scientific paper should be done in a standard form. This standard form is given by the citation style of the paper's publisher. Usually, the citation style is imposed by the editor, such as publishing in a volume of a scientific conference. Also, the selected citation style depends on the research topics (domain).

Standards or international requirements to work uniformly regarding citing references, do not exclude a certain variety in citation formats and styles in editorial practice.

ISO 690:2010 develops general rules for presenting references in all fields of science.

There are a multitude of handbooks and instruction guides, models and citation examples in text or lists of references. Broadly, there are three systems of citation.

\subsection{1 "Author-Date" System (Harvard System)}

In the text, the author's name and year of publication (number of pages if necessary) are presented between parentheses. Full references appear in alphabetical order in a list at the end of the paper.

The "Harvard system" designates a style referencing quotes in a text by the "author-date" method and it is based on Recommendations for citing and referencing published material developed by British Standards Institution (BSI). ISI 690:2010 uses this format as well as the American Chemistry Association (ACS), American Psychology Association (APA), Chicago University with Chicago and Turabian styles, also the Council of Science Editors (CSE). Universities use the general principles of the system to develop their own guides. The benefit of this system is given by the identification of an author's paper using a direct method. Unlike the Vancouver system, the "author-date" system does not cause trouble while renumbering references, in case the citation order is changed within the text. 
The main disadvantage of this system is the need of more space within the body of text and the possible distraction in case of multiple citations made at the same place.

\subsection{2 "Author-Title"/“Author-Page" Style}

It was developed for Arts and Humanities, where the paper's title and pages are more important in a citation than the publication date. This information allows analytical researchers to easily follow exact phrases in the text analysis process. A short title is required only when there are several works written by the same author. Modern Languages Association of America (MLA) prefers this format.

\subsubsection{Sequential Number System or "Author-Number" (Vancouver System)}

Citations are consecutively numbered (using Arabic numbers in parentheses or superscripts) according to the order of appearance in a text. In the several cited references, the first number assigned is maintained and a page number is indicated only if necessary. Complete citations, numbered in order of appearance in the text, are presented in a list at the end of the paper. An advantage of the Vancouver system is including numbers that do not interrupt the text flow. The main disadvantage of the system is that in the process of editing a paper, a reference added later will require renumbering citations in the text and in the references list, in this case increasing the risk of error.

\subsubsection{References in a Notes System}

Footnotes or endnotes include the bibliographic description of the source, being consecutively numbered in text (by Arabic numbers between parentheses or as superscripts). Complete references are arranged in alphabetical order in a list (bibliography) at the end of the paper.

Bibliographic notes are mainly used in the field of historical research and represent an alternative to citation in text. A disadvantage is that footnotes are often too expensive for editorial reproduction. Long notes may distract readers.

In case no citation standard is imposed, then it is mandatory to use the Romanian standard ISO 690:2010.

Regardless of the citation style, as a principle, the reference includes the same bibliographic elements, but the architecture may be different.

References can be organised in two different ways:

- References list-is a list of information sources cited in a scientific paper, numerically organised, in order of appearance in text; or 
- Bibliography - is an extended list of information sources that were consulted, and not necessarily cited, alphabetically organised according to the author's name or source's title (Ruskin University 2011).

\subsubsection{Citation "Anatomy"}

The term: "citation anatomy" was defined in the Library Workshop Manual: Sect. 4, published by Davis Schwartz Memorial Library (Davis Schwartz Memorial, 2011).

This section of the material related to the citation process is focused on the description of mandatory bibliographic elements, for the most used information sources.

The formats and examples are presented and illustrated both for printed and electronic sources, published or unpublished.

Standards used for this section are: SR ISO 690:1996 for printed information sources, SR ISO 690:1997 for electronic information sources and the Harvard style for unpublished information sources.

\subsubsection{Printed Information Sources}

\section{Printed book. Technical report. Ph.D. thesis}

Author of book. Title of book. Edition. Publishing place: Publishing house, year. ISBN.

\section{Printed book chapter}

Author of chapter. Title of chapter. In: Author of book. Title of book. Publishing place: Publishing house, year, chapter pages.

\section{Printed journal}

Title of journal. Author/editor. Edition. Fascicle (year and/or number). Publishing place: Publishing house, year. ISSN.

\section{Article in printed journal}

Article's author(s). Title of article. In: Title of journal, year, volume, number, article pages. 


\section{Standard}

Organisation name. Standard number: year. Title of standard. Publishing place: Publishing house, year.

\section{Pattern}

Name of applicant. Title of pattern. Country or office, pattern type, number. Publishing date.

\section{Paper in a conference}

Author(s) of paper. Entire title of paper. In: Publisher/organiser's name, Complete title of conference. Location (town, country), conference dates. Publishing place: Publishing house, year.

\section{Legislation document}

Jurisdiction (country, institution). Title of legislation document (document type, number, day and month, official title of law). In: Title of publication, publication date, number, pages of legislation document.

\subsubsection{Electronic Information Sources}

\section{Electronic book}

Author(s) of book. Title of book [support]. Publication place: Publishing house, year [accessing date]. Availability and accessibility.

\section{Chapter in electronic book}

Author(s) of chapter. Title of chapter. In: Author(s) of book. Title of book [online]. Publishing place: Publishing house, year [accessing date]. Location. Availability and accessibility.

\section{Electronic journal}

Title of journal [online]. Edition. Publishing place: Publishing place, year [accessing date]. Availability and accessibility.

\section{Article in electronic journal}

Author(s) of article. Title of article. Title of electronic journal [online]. Year, volume (publication number) [accessing date]. Article pages. Availability and accessibility. 


\section{Forums}

Forum title [online]. Publishing place: Publishing house, publishing date [accessing date]. Availability and accessibility.

\section{Electronic messages (e-mail)}

Sender's name. Title of message [online]. Recipient's name. Date of sending (including time) [access date]. Availability and accessibility.

\subsubsection{Other Information Sources}

If other information sources are used in developing a scientific paper, this aspect should be recognised and sources must be mentioned as references.

As an example, if an investigation is the result of cooperation with other experts or institutions/centres/research laboratories, then this situation should be recognised.

Harvard style includes citation of situations such as information coming from information sources that are: unpublished or in process of publication; oral or personal information; or comments on personal blogs, online video transmissions.

\subsubsection{Unpublished Information Sources}

Author, year. Title of paper. Unpublished manuscript/manuscript submitted for publication.

SPUD, I. H. Contrastive analysis: A comparison of Pig Latin and English. 1999. Unpublished manuscript.

ROOSEVELT, F. Childhood acquisition of Pig Latin by native speakers of English. Manuscript submitted for publication.

\section{Oral Presentation}

Name of speaker. Title of presentation. Presentation in Title of conference, location (town, country), presentation date.

VONCILĂ, Mioara. Un model de organizare a bibliotecilor universitare ca sisteme întredeschise. Prezentare susţinută în cadrul Lucrărilor Conferinței Naţionale a Asociaţiei Bibliotecarilor din România, Braşov, Romania, 10th September 2004.

\section{Informal Publication}

Author, year. Title of publication [prospect/circular]. Publication place: Publishing house.

Anglia Ruskin University, August 2007. Using the Cochrane Library [leaflet]. Cambridge: Anglia Ruskin University [2]. 


\section{Publications on Internet (Web Pages)}

Author/source, year. Title of web document/webpage [online]. (update time). Available at: web address [accessing date].

London South Bank University, 2009. How to do your Referencing: Numerical Style [online]. Available at: http://www.lsbu.ac.uk/library/helpsheets/hs28.pdf [cited 28 December 2010] [10].

\section{Blogs/Weblogs}

Author, year. Title of blog entry (posted message). Title of blog [blog]. Date of blog entry post. Available at: web address [accessing date].

WHITTON, Felix, 2009. Conservationists are not making themselves heard. Guardian.co.uk Science Blog [blog] 18 June. Available at: http://www.guardian.co. uk/science/blog/2009/jun/18/conservation-extinction-open-ground [Accessed 23 June 2009] [10].

\section{Online Video Transmissions}

Name of producer, year. Title of video transmission [video online]. Available at: web address [accessing date].

\subsection{Using Microsoft Office Word-References}

There are several electronic applications for references management: Reference Manager, EndNote, CrossReff. These applications must be purchased. We will demonstrate a free tool for those using Microsoft Office.

"References" is a useful instrument for the management of the information resources used and for generating a bibliography. In Fig. 8.4, all terms used in the program operation are translated.

\subsubsection{Steps for Automatic Bibliography Generation}

\section{Adding Reference to the Document}

When a new citation is added to a document, a new source is automatically created, appearing in the list of bibliographic references. On the menu bar choose REFERENCES (Fig. 8.2).

In REFERENCES menu, group CITATIONS AND BIBLIOGRAPHY, click on the arrow near STYLE and choose the style you wish to use. Microsoft Office Word 2007 offers the user the possibility of generating bibliographic references in various styles: APA, Chicago, GB7714, GOST—sort by name, GOST—sort by 


\begin{tabular}{|c|}
\hline Show all bibliography fields \\
\hline Create Sourse \\
\hline Add new placeholder \\
\hline Add new source \\
\hline Bibliography \\
\hline Search libraries \\
\hline Search \\
\hline Citation 8 bibliography \\
\hline Click \\
\hline Manage sources \\
\hline Insert bibliography \\
\hline Insert citation \\
\hline Language \\
\hline Master list \\
\hline Current list \\
\hline References \\
\hline Sort by \\
\hline Style \\
\hline Type of source \\
\hline
\end{tabular}

Fig. 8.2 The elements used in information management

title, ISO 690 - citations by first element and date, ISO 690 — numeric citations, MLA, SISTO2, Turabian (Fig. 8.3).

\begin{tabular}{|c|c|}
\hline Abbreviation & Style \\
\hline APA & American Psychological Association \\
\hline Chicago & The Chicago Manual of Style \\
\hline GB7714 & Standardisation Administration of China \\
\hline GOST—Name Sort & $\begin{array}{l}\text { The Federal Agency of the Russian Federation on Technical } \\
\text { Regulating and Metrology }\end{array}$ \\
\hline GOST_-Title Sort & $\begin{array}{l}\text { The Federal Agency of the Russian Federation on Technical } \\
\text { Regulating and Metrology }\end{array}$ \\
\hline $\begin{array}{l}\text { ISO } 690-\text { First } \\
\text { Element and Date }\end{array}$ & International Organisation for Standardisation \\
\hline $\begin{array}{l}\text { ISO } 690 \text { - Numerical } \\
\text { Reference }\end{array}$ & International Organisation for Standardisation \\
\hline
\end{tabular}




\begin{tabular}{l|l}
\multicolumn{1}{c|}{ (continued) } & \\
\hline Abbreviation & Style \\
\hline MLA & Modern Language Association \\
\hline SIST02 & $\begin{array}{l}\text { Standards for Information of Science and Technology by Japan } \\
\text { Science and Technology Agency }\end{array}$ \\
\hline Turabian & Turabian Style
\end{tabular}

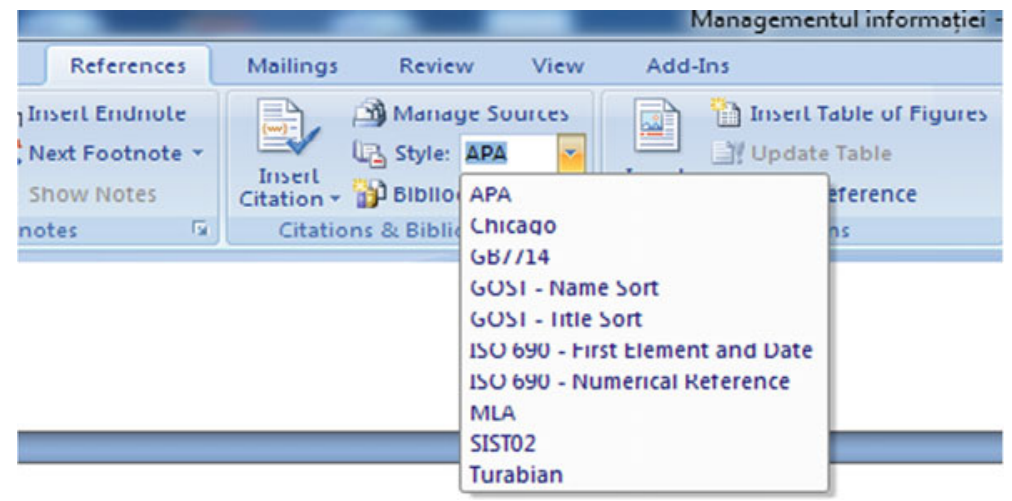

Fig. 8.3 Citations styles in Microsoft Office Word

Click in the place of the future citation. In REFERENCES menu, group CITATIONS AND BIBLIOGRAPHY, click on INSERT CITATION and select the necessary option: ADD NEW SOURCE or ADD NEW PLACEHOLDER (Fig. 8.6).

After click on ADD NEW SOURCE, the menu CREATE SOURCE click on the arrow near SOURCE TYPE, in drop-down menu, Fig. 8.4.

Select source type: book, section of book, article in a journal, article in periodical, conference proceedings, report, Web site, document in Web site,

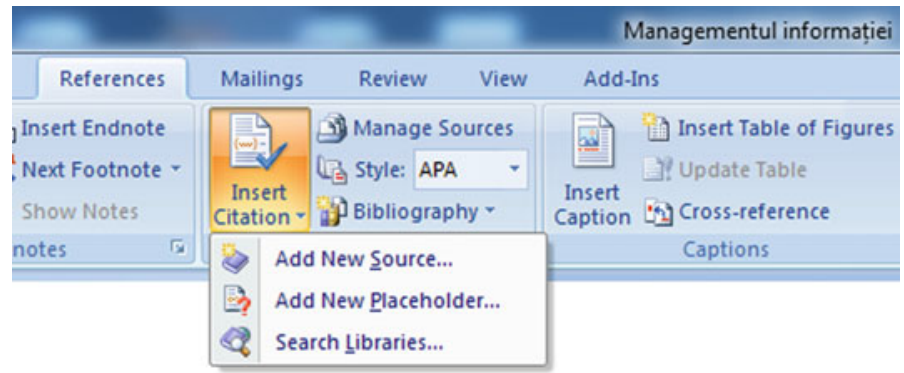

Fig. 8.4 Insert bibliographic references 


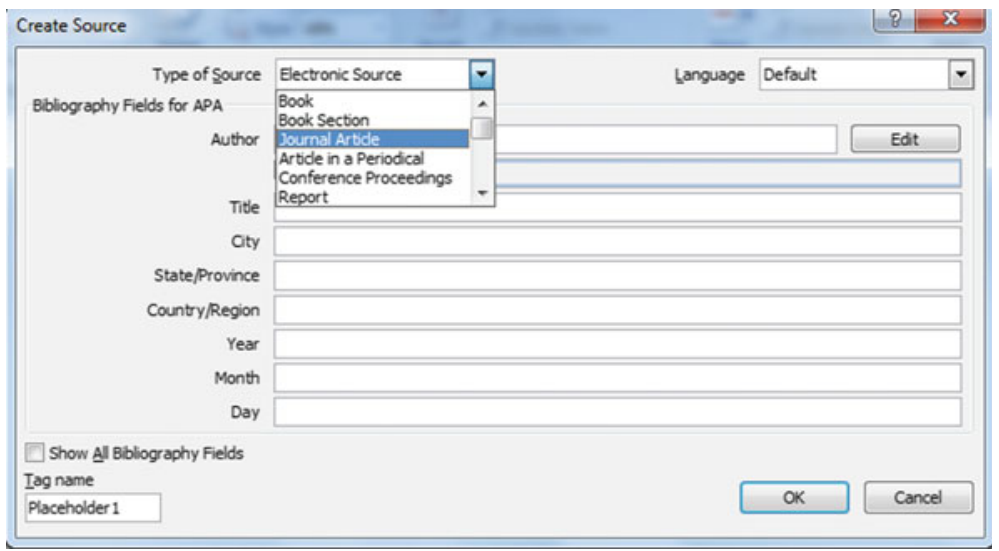

Fig. 8.5 Selecting source type

electronic source, art edition, audio recording, representation, film, interview, pattern, file, miscellaneous (Fig. 8.5). Also, select the publication language using LANGUAGE.

Fill in the bibliographic data for the document in the respective fields. In order to add more information about the document click on the selection box SHOW ALL BIBLIOGRAPHY FIELDS. Recommended fields are marked by an asterisk. After filling in the bibliographic data, click on OK (Figs. 8.6, 8.7).

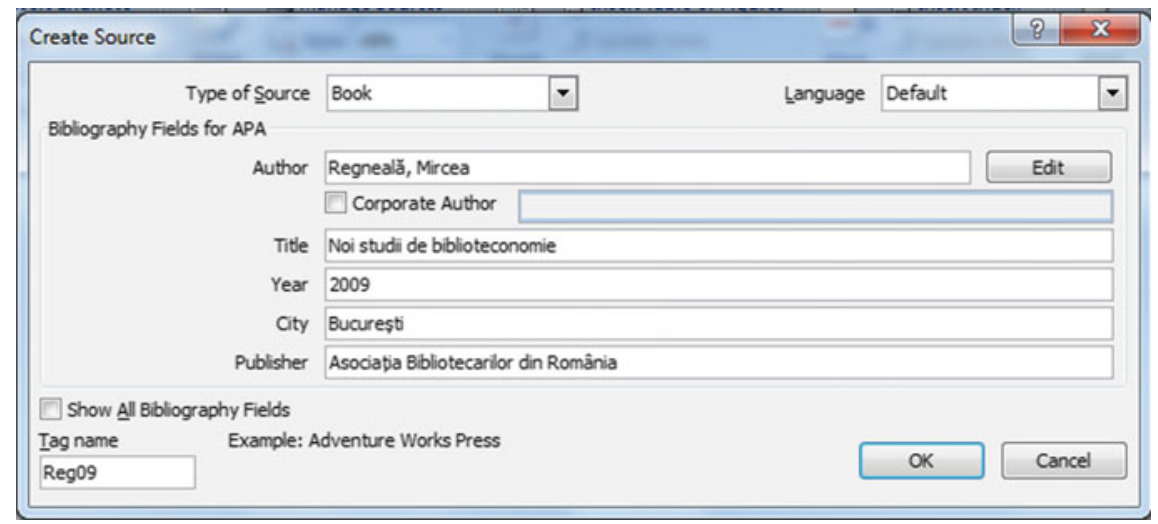

Fig. 8.6 Inserting a book 


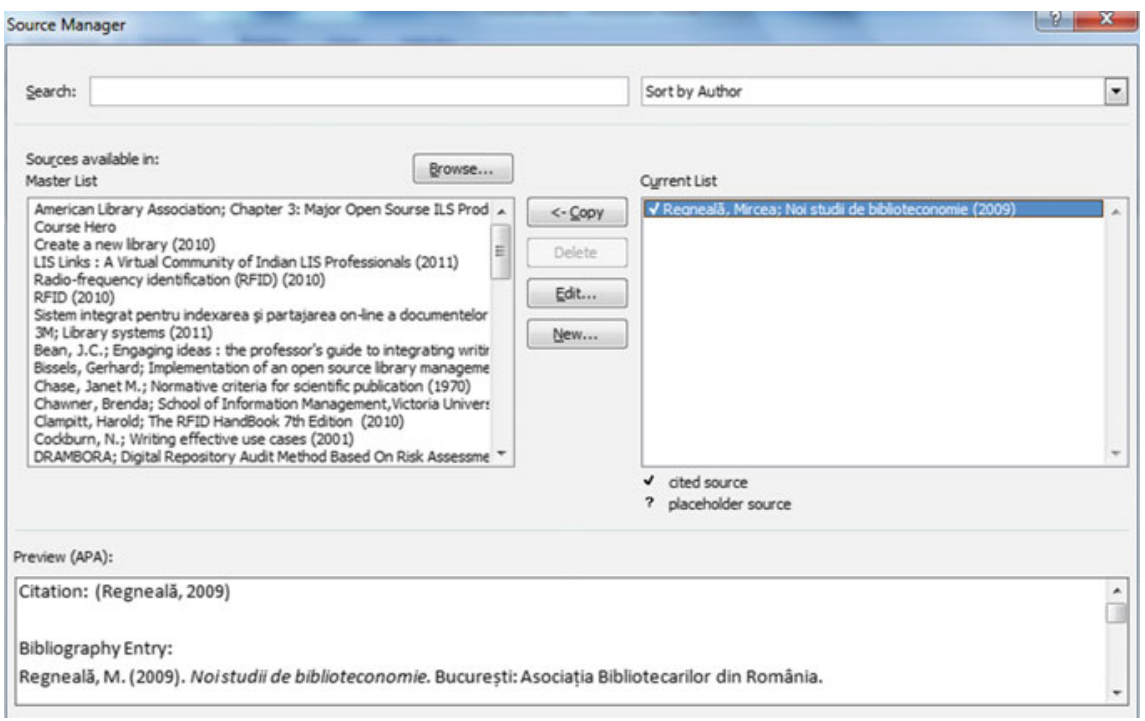

Fig. 8.7 Master list and current list

\section{Search for Cited Sources}

- In order to search for cited sources, select: CITATIONS REFERENCES and BIBLIOGRAPHY SOURCE MANAGER.

- SOURCE MANAGER includes two lists: MASTER LIST and CURRENT LIST.

When a new document is opened, all sources cited in previous documents are shown in MASTER LIST (Fig. 8.8).

- If the opened document already contains citations, then MASTER LIST includes all the resources consulted during the research, both in the current document and in previous documents. CURRENT LIST contains all cited sources in the current document.

- In order to find a certain source, select the sort type in the drop-down menu: BY AUTHOR, BY TAG, BY TITLE, BY YEAR. Look for the required source in the resulting list (Fig. 8.9).

- If you introduce the title or author of the source you are looking for in the SEARCH box, the list of the cited sources narrows in order to obtain the search term. 


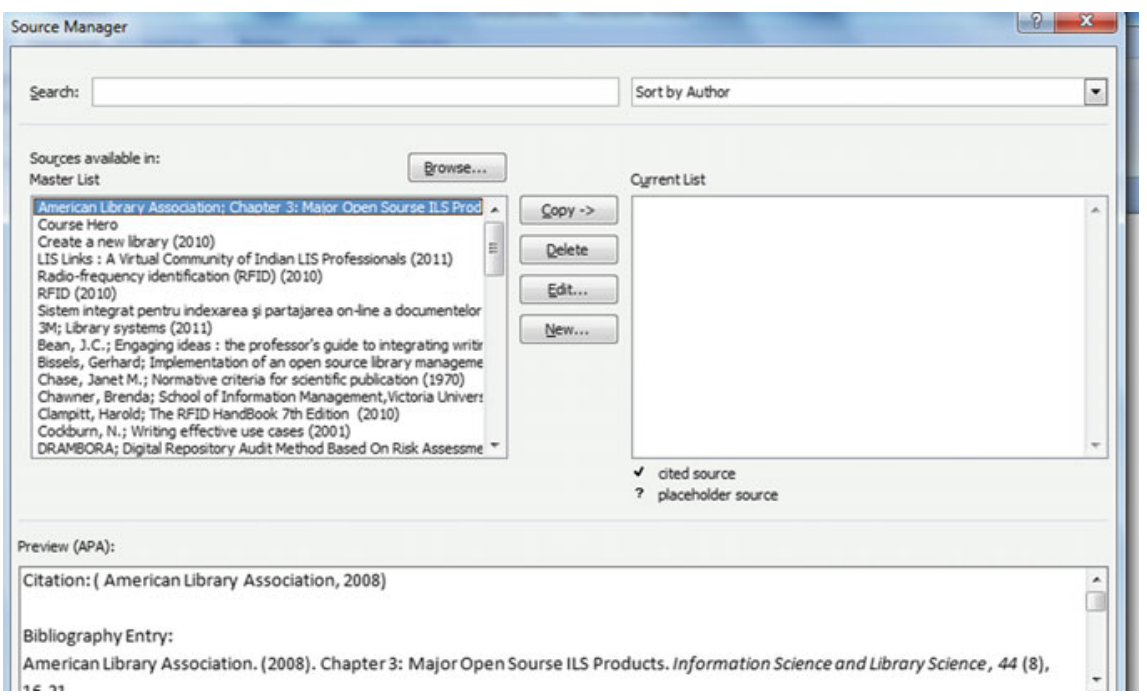

Fig. 8.8 Master list

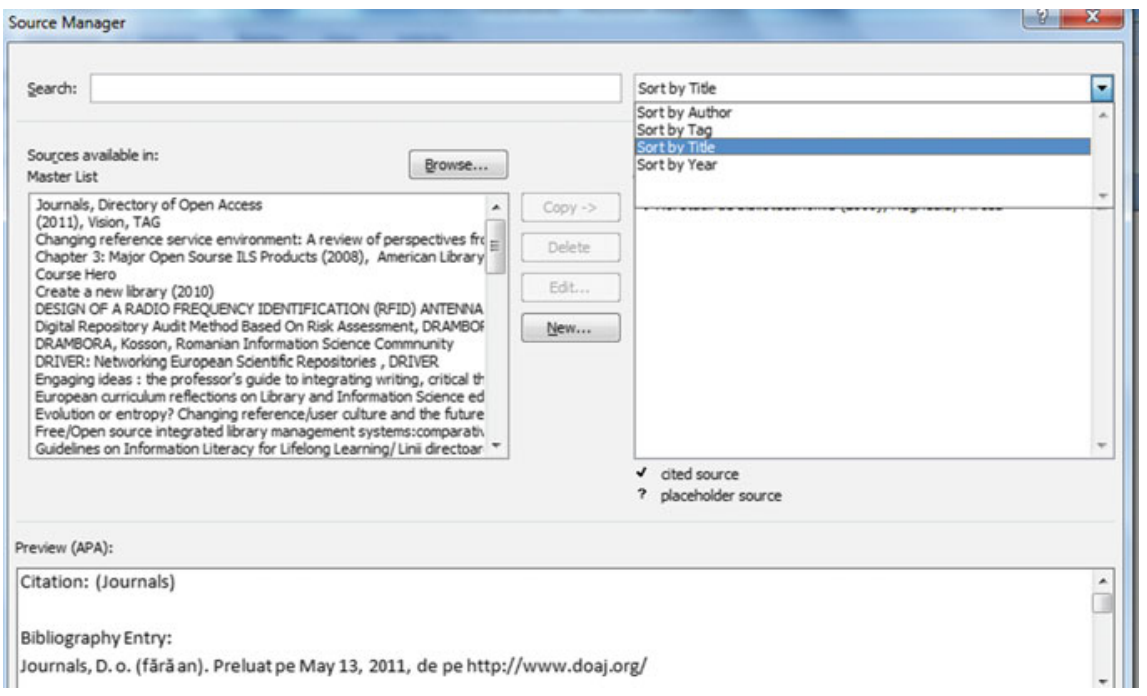

Fig. 8.9 Search sort in master list 


\section{References Editing}

- In order to edit the references, select: REFERENCES, CITATIONS AND BIBLIOGRAPHY - SOURCE MANAGER.

- Under the CURRENT LIST click on the placeholder you wish to change or fill in.

- Click the EDIT button.

- Click the arrow near the TYPE OF SOURCE.

- Fill in or change the necessary data.

- After editing the bibliographic data, click on OK.

- All the changes are automatically shown in the bibliography.

\section{Creating the List of References}

- Creating the list of references is possible by a click made at any time after introducing one or more sources.

- Set the cursor in the text at the place where the list of references will appear (usually at the end of the paper or chapter).

- Select: REFERENCES CITATIONS AND BIBLIOGRAPHY.

- In order to insert the bibliography into the document, click on INSERT BIBLIOGRAPHY (Figs. 8.10, 8.11).

- In order to change style, select the preferred style: APA, ISO, MLA etc., using the STYLE icon. The references list is automatically updated.

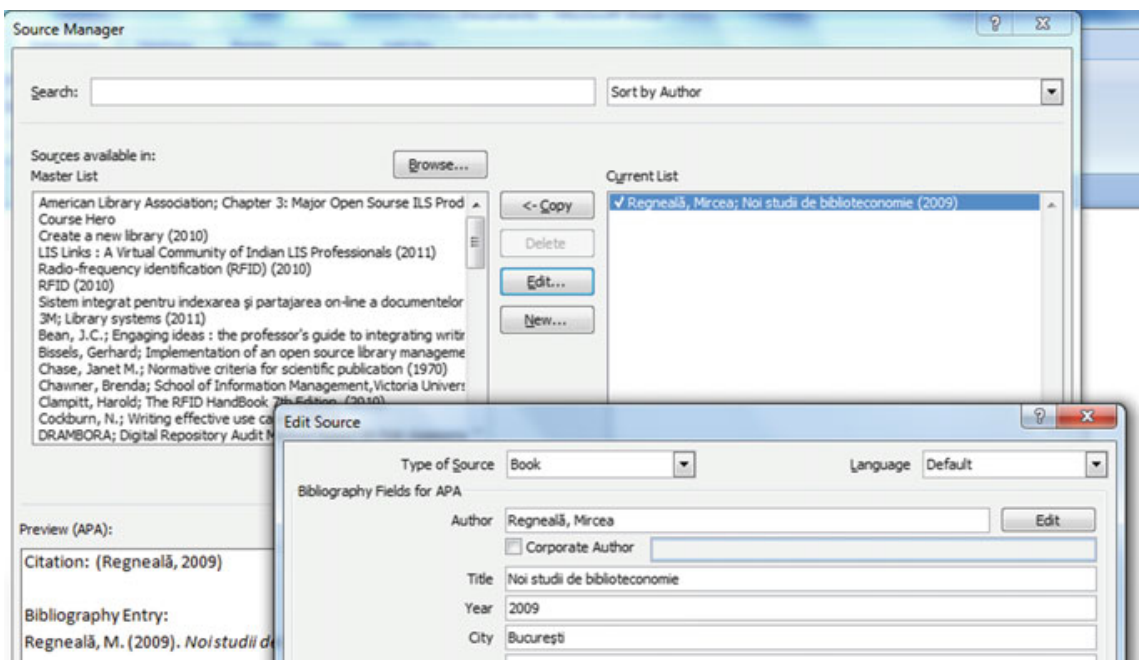

Fig. 8.10 References editing 
Fig. 8.11 Insert

bibliography

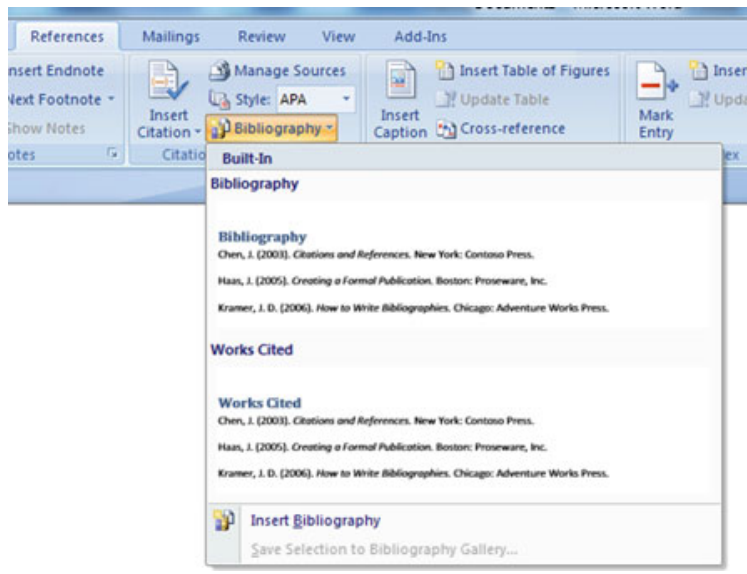

\subsection{Other Publications Identification Elements: International Codes for Publications}

\subsubsection{International Standard Book Number}

The International Standard Book Number (ISBN) is used as a key-element of recording and inventory systems for editors, distributors, libraries and other organisations. It was adopted in 1970 as an international standard ISO 2108. In Romania, the standard numbering system of books was introduced in 1989. ISBN identifies the editor, specific title, edition and book format. Once it is assigned, the ISBN number cannot be changed, replaced or reused. It has no legal value, meaning that it does not offer copyright protection. http://www.isbn.org/standards/home/ index.html.

The ISBN consisted of ten digits until 1st January 2007 when it was increased to 13 digits, divided into five segments (separated by dashes):

- Segment 1: EAN prefix or code (European Article Number) may be only 978 or 979;

- Segment 2: identification number of the group representing the country, geographical area or language area that participates in the ISBN system. This element may have between one and five digits;

- Segment 3: editor identification number (may have up to seven digits);

- Segment 4: title identification number in editor's production (may have up to six digits);

- Segment 5: control position that allows validity check of the ISBN code (a single digit that mathematically validates the integrity of the number considered as a whole). 
Being a National ISBN Agency, Romanian National Library distributes ISBN codes based upon standards that are approved and applied by the International ISBN Agency from London.

For printed publication, the ISBN number should be on the reverse of the title page, lower left part, in CIP description and on the back cover. The ISBN number of an electronic document is displayed on the title presentation page or its equivalent, on CD-ROM (cover or disk) and on the presentation page.

\subsubsection{International Standard Serial Number}

The International Standard Serial Number (ISSN) is the international standard code of the serial publications like: newspapers, journals, annals, bulletins, and scientific papers. ISSN was released and developed under the United Nations International Scientific Information System programme (UNISIST) created together with UNESCO. In 1975 the international standard ISO 3297 was adopted.

The ISSN International Centre based in Paris records every ISSN code together with the publication title and bibliographic description in a specialised database: The ISSN Register. This database, constantly updated within the network has an annual growth between 40,000 and 60,000 ISSN numbers.

The ISSN network consists of national centres, which are responsible for the efficient continuation of the ISSN system, achieving bibliographic consistency. As an ISSN National Centre, the Romanian National Library distributes ISSN in Romania.

An ISSN number consists of two segments each made of four digits (Arabic numbers) separated by a dash, preceded by the ISSN acronym, followed by a space. The last element (control element) is $\mathrm{X}$.

According to standard ISO 3297:2007, ISSN liaison number (ISSN-L) is assigned to a serial publication in order to regroup different physical parts of the respective resource, regardless of the number of parts (each of these parts should have an unique ISSN number www.issn.org.

\subsubsection{International Standard Music Number}

The International Standard Music Number (ISMN) is an index applicable to printed musical publications.

Each standardised international number for written or printed musical publications, should be preceded by letters ISMN and each component element should be separated by the following using a space or a dash as in the following examples: ISMN M 57110051 3, ISMN M-01-123456-3. 


\subsubsection{Digital Object Identifier}

The Digital Object Identifier (DOI) represents an identification system of a work produced in a digital environment. The DOI system is currently being standardised using ISO. The international standard project ISO/DIS 26324 was approved at the end of 2010.

The DOI International Foundation (IDF) was established in 1998, in order to develop an infrastructure, policies and procedures framework to support suppliers' needs and to protect intellectual property in the digital environment http://www.doi. org/.

A DOI number consists of a prefix and a suffix, separated by a slash. The prefix starts with " 10 ". The next element of the prefix identifies the name of the organisation that wishes to record the DOI number. Prefix blocks are assigned by the DOI Registration Agency. A suffix is chosen by the editor, by identifying the specific object. It can be a simple sequential number or an already established code is used (ISBN or any other property ID), that allows integration based on existing systems. This looks as follows: [“doi” acronym with regular letters, followed by a colon (:) no space].

Each DOI is unique and final. A document keeps its own DOI for its entire existence and, in case of document elimination, the number can never be used again.

\section{Suggested Teaching}

\section{Warm-Up}

Name crossword.

The teacher divides the participants into four groups. Each group will receive sheets of paper and pencils. The trainer urges the groups to write their names under each other in order to form a crossword of these names. Recommended working time is three minutes. Teams will present their results at the end of the activity. The trainer will congratulate the participants for their involvement.

\section{Teaching Activities}

The learning situation in which students will be involved will require the use of encoding, storage and recognition of information processes from memory.

Thus, the teacher will announce the title of the lesson and write on the whiteboard or flip chart the lesson objectives. The trainer will explain the meaning of information management. He will present Fig. 8.1. Information use, either by writing on the whiteboard or with a poster printed before the lesson. The teacher will ask students to transcribe it into their notebooks and memorise it or to be familiar with it. 
Through the conversation and explanation method, the teacher will go through (8.1) Using information in the research process. He will require trainees to note and retain the elements bolded in the unit's summary. The teacher will ask the question: "Why do you think the bibliographic description rules are necessary? What purpose do they serve?"

The use of the bunch method, which is widely described in Chap. 10 of this volume, becomes a useful tool at this time of teaching. The method is a teaching-learning technique that aims to stimulate learners to think freely and discover connections between ideas. In a first phase, the teacher can demonstrate how the first level of the bunch is formed, and then, for the next steps, encourage students to build new ideas associations.

Sequence (8.1.2) Principles of Describing Information Sources can be read from the support course and it can be transcribed as a bunch by a pair of two students Analogy will be used as a didactic strategy, in order for the trainees to copy the previous approach based on the transfer of information and the similarity with the previous situation.

Other graphical organisers, useful in teaching the sequence (8.1.3) Citation Methods, are tree schemes. These may be horizontal or vertical. Among the horizontal ones, we mention: horizontal cause-effect tree, and the type of situationproblem-explanation, classification type. Some of the best-known vertical tree schemes are Tree of Ideas and Concept Tree.

These graphic organisers allow information to be arranged according to logical criteria such as classification, attributes of a phenomenon, or determinant situations. Lines or arrows represent relationships between concepts, they can emphasise and show the direction of influence between them. An example of such a network is shown in Fig. 8.12 Examples of the Elements of a Graphical Organizer.

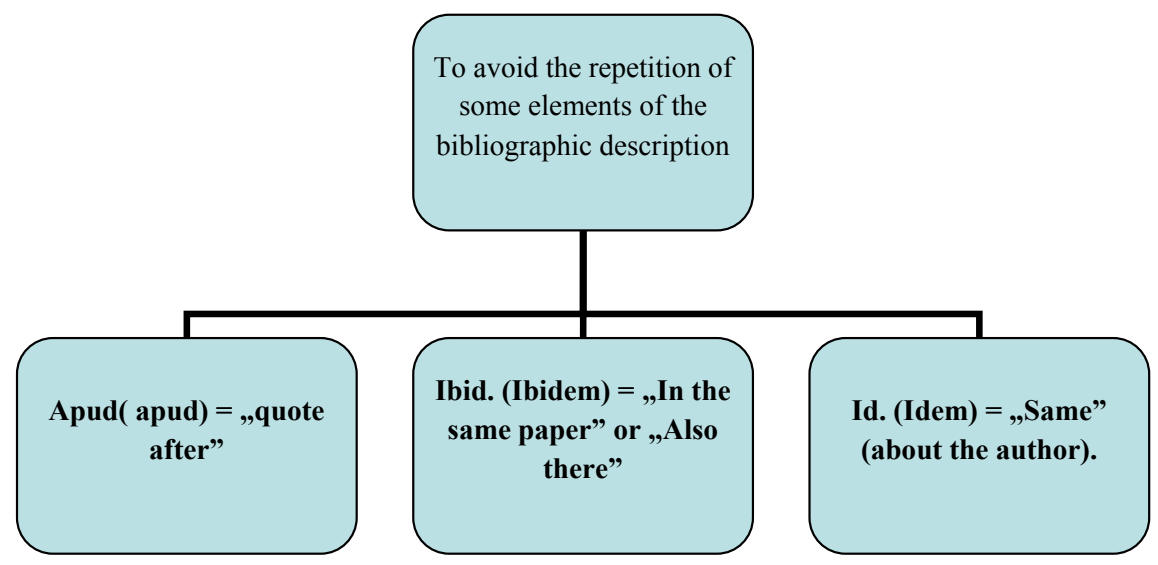

Fig. 8.12 Example of the elements of a graphical organizer 
Activity (8.2) Citation Styles can be taught by the Mosaic method or the Cube method. If the Mosaic method is used, the participants will be divided into four relatively homogeneous groups. Within the groups, there will be another division. Regardless of the number of participants, they will count from one to four, repeating the counting sequence where necessary. Students will be divided into four other groups, reminding them not to forget the composition of the original groups.

They will receive edited text from the course summary, equivalent at the level of difficulty and size. The task of the groups is to become experts in the course given, and then, after completing their activity, return to the original groups and teach their colleagues the activity for which they were responsible. The role of the teacher is to facilitate the work of the experts and mentor their work. He can intervene whenever necessary.

If the cube method is used, the group is divided into six relatively homogeneous subgroups. The cube will be built before the course starts. Each facet will represent a work field: describe, compare, analyse, associate, apply, or discuss. The subgroups will have the task of solving one of the requirements on the cube faces. After all groups complete the tasks, they will designate a member of the group who will communicate the results (the information can be noted on the flip chart or whiteboard).

Example of tasks:

- Describe References in notes system;

- Compare Harvard and Vancouver citation styles;

- Analyse printed information sources;

- Associate appropriate quotation methods for an oral presentation of your choice from a student's scientific conference, your favorite blog, or a online video transmission;

- Apply all citation styles described in the course for an Information Literacy manual of your choice; or

- Discuss why so many citation styles are used.

Course Sequence (8.3) Using Microsoft Office Word-References will be done by demonstration and modeling. The teacher will use a computer with Microsoft Office Word installed, projecting the image of an accessed Word page with a video projector. We recommend that the trainer verbalise each stage and explain each command he gives in the program. If there are requests or questions from the trainees, he will stop and give the necessary explanations.

Modeling as a method involves students repeating what the teacher has demonstrated. Therefore, it would be ideal if this course would be held in a room equipped with sufficient computers for one for each participant. At the end of the activity, students will be given two similar situations for practising newly formed skills. 
For the activity (8.4) Other Publications Identification Elements: International Codes for Publications, the trainer will divide the participants into four groups. Each group will receive two volumes, one with an ISBN and one with an ISSN. The task of the students will be to discover the differences between the two volumes and thus the two different identifiers.

At the end of the activity, after each group will communicate the differences found. The relevant identifying elements will be explained to the students for the International Standard Music Number and the Digital Object Identifier.

\section{Review}

Students will be asked to fill in the following table in groups:

\begin{tabular}{l|l}
\hline Criterion & My notes \\
\hline Course summary/main ideas & \\
\hline Keywords & \\
\hline Questions & \\
\hline Connections & \\
\hline Personal reflections & \\
\hline
\end{tabular}

\section{Applications}

1. Identify in scientific papers recently read at home, the following types of sources: course notes, a PowerPoint presentation, a research article, and a book or specialty literature.

2. Cite the sources indicated above through the MLA, APA, or ISO systems.

3. Analyse the differences between the sources specified in application task 1, using the following criteria: page number, generality level, structure of information, and number of citations.

4. Analyse a highly rated article in your field of study. Make a list of the main difficulties you encounter when reading such an article.

5. Find a program that you can use on your personal computer, where you can make a bibliography of a scientific document with ease. Explain how it works and argue for your choice. 


\section{Evaluation}

\begin{tabular}{l|l}
\hline Question & Answer \\
\hline For what will I use this course? & \\
\hline Did I correctly understand the knowledge? & \\
\hline Have I ever faced such learning situations? & \\
\hline How did I manage other situations? & \\
\hline What techniques, procedures have I used then, and can I use them now? & \\
\hline Can I learn alone or will I need help? & \\
\hline How will I know if I have succeeded? &
\end{tabular}

\section{References}

Davis Schwartz Memorial. (2011). Library. Library workshop manual: Section 4. Davis Schwartz Memorial Library of the C.W. Accessed on December 21, 2011. http://www2.liu.edu/cwis/ cwp/library/workbook/evaluate.htm\#citing.

Ruskin University, Library. (2011). Guide to the Harvard Style of Referencing. Accessed on November 12, 2011. http://libweb.anglia.ac.uk/referencing/harvard.htm.

STAS 6443-1988: Prezentarea articolelor din publicaţiile periodice ştiinţifice şi tehnice şi din alte publicaţii seriale similare. București: IRS.

Ursachi, L., \& Scutelnicu, E. (2011). Citation models of the information source. Brașov: Editura Universităţii „Transilvania” din Braşov.

\section{Bibliographic Recommendations}

IOE Libguides: Mendeley: Home. (2019). Libguides.Ioe.Ac.Uk. Accessed February 15, 2019. https://libguides.ioe.ac.uk/mendeley.

IOE Libguides: Zotero: Home. (2019). Libguides.Ioe.Ac.Uk. Accessed February 15, 2019. https:// libguides.ioe.ac.uk/zotero. 
Open Access This chapter is licensed under the terms of the Creative Commons Attribution 4.0 International License (http://creativecommons.org/licenses/by/4.0/), which permits use, sharing, adaptation, distribution and reproduction in any medium or format, as long as you give appropriate credit to the original author(s) and the source, provide a link to the Creative Commons license and indicate if changes were made.

The images or other third party material in this chapter are included in the chapter's Creative Commons license, unless indicated otherwise in a credit line to the material. If material is not included in the chapter's Creative Commons license and your intended use is not permitted by statutory regulation or exceeds the permitted use, you will need to obtain permission directly from the copyright holder.

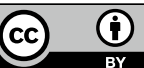

